\title{
Polymicrobial tenosynovitis with Pasteurella multocida and other Gram negative bacilli after a Siberian tiger bite
}

\author{
P A Isotalo, D Edgar, B Toye
}

\begin{abstract}
Mammalian bites present a considerable clinical problem because they are often associated with bacterial infections. Pasteurella multocida is a microorganism that commonly infects both canine and small feline bites. Zoonotic infections developing after large feline bites have been recognised, although their reports are limited. We describe a 35 year old man who was bitten by a Siberian tiger and who developed infectious tenosynovitis secondary to P multocida, Bergeyella (Weeksella) zoohelcum, and Gram negative bacteria most like CDC group EF-4b and comamonas species. The latter three bacteria have not been isolated previously from large feline bite wounds. (f Clin Pathol 2000;53:871-872)
\end{abstract}

Keywords: animal bite; zoonotic infection; Pasteurella multocida; Bergeyella zoohelcum

Zoonotic infections developing after cougar, lion, and tiger bites have been recognised, although their reports are limited..$^{1-3}$ Bites of small and large felines have predominantly been associated with Pasteurella multocida infection, ${ }^{1-8}$ although other bacteria have also been identified as pathogens of tiger bite wounds. ${ }^{12}$ We report the case of a patient who was bitten by a tiger and who developed a polymicrobial tenosynovitis.

\section{Case report}

A 35 year old, previously healthy man was bitten once on his left palm by an adult Siberian tiger (Panthera tigris altaica) that he was training. The tiger had been raised in Canada and had no previous disease. The patient's medical history was unremarkable, except for a three day history of uncomplicated upper respiratory tract infection. He presented to the emergency department of a rural hospital 7.5 hours after sustaining the feline bite. Because of concerns about tendon involvement he was transferred to our tertiary care centre, where he complained of severe pain, especially on flexion of his left fourth and fifth fingers. On examination, he had a tympanic temperature of $38.3^{\circ} \mathrm{C}$. Examination of the left hand revealed a tender $2 \mathrm{~cm}$ longitudinal laceration of the midpalm, which extended from the area of the fourth carpometacarpal joint to the midpalmar crease, with a cloudy white discharge. The first three digits had normal function. The fourth and fifth digits were exquisitely tender to passive extension and flexion, although there was no tenderness on palpation of these digits. Mild superficial abrasions surrounded the left wrist. There was also severe pain on wrist flexion and extension with both ulnar and radial deviation of the wrist. Neurovascular examination of the left hand was normal. There was no evidence of lymphangitis or axillary lymphadenopathy. Radiological examination of the left hand and wrist revealed no fractures or bony abnormalities. No foreign body or subcutaneous air was identified. Laboratory investigations revealed a leucocyte count of $13.7 \times 10^{9} /$ litre with a neutrophil count of $12.1 \times 10^{9} /$ litre. Haemoglobin, platelet count, and serum electrolytes were all within laboratory reference ranges.

The patient was admitted with a diagnosis of infectious tenosynovitis. Within an hour of admission, the patient's temperature rose to $38.9^{\circ} \mathrm{C}$. His wound was cultured and then irrigated with normal saline and dressed with Polysporin and Kerlix mesh. The patient was given intravenous (IV) cefazolin at $1 \mathrm{~g} / 8$ hours and gentamicin $80 \mathrm{mg} / 8$ hours for a total of 72 hours. After three days of IV antibiotic treatment, the swelling and tenderness of his left hand decreased substantially and he regained almost full flexion and extension of his fourth and fifth digits. He was discharged on a 10 day course of amoxicillin-clavulanic acid $500 \mathrm{mg}$ orally three times a day.

Blood cultures were negative, but aerobic cultures from the wound grew P multocida, Bergeyella (Weeksella) zoohelcum, and two other Gram negative bacilli. These were subsequently identified as most like CDC group $\mathrm{EF}-4 \mathrm{~b}$ and comamonas species by the national laboratory for bacteriology, Laboratory Centre for Disease Control in Ottawa, Canada on the basis of biochemical reactions and cellular fatty acid composition data. Subspeciation of the $P$ multocida isolate was not performed. Anaerobic cultures of the wound were not obtained.

\section{Discussion}

Pasteurella multocida has been isolated as part of the normal fang flora of many large felines. ${ }^{1}$ Thus, it is not surprising that previously published reports of wound infections after large feline bites have emphasised this pathogen. Such infections also tend to be polymicrobial and other organisms that have been reported from large feline bite wounds have included: Acinetobacter spp, Escherichia coli, Moraxella spp, Pasteurella spp (other than P multocida), Staphylococcus aureus, and viridans streptococci. ${ }^{1-3}$ However, other less com-
Accepted for publication 10 April 2000 
monly encountered bacteria, some of which might be difficult for clinical laboratories to identify, may also be agents of large feline bite infections. There have been no previous reports of isolating $B$ zoohelcum (formerly Weeksella zoohelcum), ${ }^{9}$ CDC group EF-4b, or Comamonas spp from large feline bite wounds. Bergeyella zoohelcum and CDC group EF-4b, however, have been reported after dog and cat bites, although Comamonas spp has not been reported in this clinical setting. ${ }^{5-8}$

CDC group EF-4b is a non-fermentative Gram negative coccoid to short rod that was originally classified as eugonic fermenter group 4 (EF-4), along with the glucose fermenting CDC group EF-4a. ${ }^{10}$ Most clinical isolates of CDC group EF-4b have been from dog and cat bite wounds. Comamonas spp are ubiquitous, environmental Gram negative bacilli that have generally been considered non-pathogenic, although they have occasionally been associated with clinically relevant polymicrobial infections. ${ }^{11}$

Mammalian bites are a considerable clinical problem and account for up to $1 \%$ of all emergency room visits in the USA. ${ }^{4}$ Canine bites comprise most of the mammalian bites (70 $90 \%$ ), but are less susceptible to infection than feline bites. ${ }^{4-7}$ Pasteurella multocida is commonly associated with feline and canine bites, although most bite wound infections are polymicrobial, with a median of five bacterial isolates in each culture. ${ }^{8}$ This case emphasises the polymicrobial nature of bite wounds. Although bites of large felines are rare, it is important to characterise their oral flora and to identify bacterial pathogens from bite wounds to provide guidelines for appropriate antimicrobial treatment. There appears to be a similarity between the bacteriology of large feline bites and that reported for small felines. Although $P$ multocida is a common pathogen, ${ }^{1-3}$ the polymicrobial nature of large feline bite wounds necessitates more than penicillin as empirical treatment. Our patient was treated with IV cefazolin and gentamicin. However, first generation cephalosporins, especially the oral agents, are not recommended for bite wound infections caused by $P$ multocida. ${ }^{12}$ The higher blood concentrations of parenteral cefazolin might have been sufficient to treat our patient, but the adequacy of this treatment cannot be guaranteed for all $P$ multocida isolates. Vigorous wound irrigation might also have contributed to our patient's response. Although susceptibility testing of the isolates cultured from our patient was not performed, it would appear that recommendations for the empirical treatment of cat bites with agents such as a $\beta$-lactam $/ \beta$-lactamase inhibitor combination would also be a reasonable approach to the treatment of large feline bites.

We thank F Huot for her excellent secretarial support and Dr K Bernard and her staff for assistance in organism identifications.

1 Woolfrey BF, Quall CO, Lally RT. Pasteurella multocida in an infected tiger bite. Arch Pathol Lab Med 1985;108:7446.

2 Burdge DR, Scheifele D, Speert DP. Serious Pasteurella multocida infections from lion and tiger bites. $¥ A M A$ multocida infections

3 Kizer KW. Pasteurella multocida infection from a cougar bite: a review of cougar attacks. West f Med 1989;150;8790.

4 Tan JS. Human zoonotic infections transmitted by dogs and cats. Arch Intern Med 1997;157:1933-43.

5 Griego RD, Rosen T, Orengo IF, et al. Dog, cat and human bites: a review. F Am Acad Dermatol 1995;33:1019-29.

6 Aghababian RV, Conte JE, Jr. Mammalian bite wounds. Ann Emerg Med 1980;9:79-83.

7 Goldstein EJC. Bite wounds and infections. Clin Infect Dis 1992;14:633-40.

8 Talan DA, Citron DM, Abrahamian FM, et al. Bacteriologic analysis of infected dog and cat bites. $N$ Engl f Med 1999; 340:85-92.

9 Vandamme P, Bernardet J-F, Segers P, et al. New perspectives in the classification of the flavobacteria: description of Chryseobacterium gen. nov., Bergeyella gen. nov. and Empedobacter nom. rev. Int f Syst Bacteriol 1994; 44:827-31.

10 Schreckenberger PC, von Graevenitz A. Acinetobacter, Alcaligenes, Moraxella, Methylobacterium, and other nonfermentative gram-negative rods. In: Murray PR, Baron EJ, Pfaller MA, et al, eds. Manual of clinical microbiology.
Washington: ASM Press, 1999:539-60.

Gilligan PH, Whittier S. Burkholderia, Stenotrophomonas, Ralstonia, Brevundimonas, Comamonas, and Acidovorax. In: Murray PR, Baron EJ, Pfaller MA, et al, eds. Manual of clinical microbiology. Washington: ASM Press, 1999:52638 .

12 Weber DJ, Wolfson JS, Swartz MN, et al. Pasteurella multocida infections. Report of 34 cases and review of the literature. Medicine 1984;63:133-54. 